\title{
The basic conditions of development of sports economy and
}

\section{countermeasure research}

\author{
LiHong Sun \\ College of physical education, Shandong University of Finance And Economics, Jinan Shandong \\ 250014
}

Keywords: sports economy; The basic conditions; countermeasures

\begin{abstract}
With the development of modern social productive forces and people consumption idea transformation, comply with the demand of market consumption, sports economy has become an important power to promote China's national fitness strategy implementation.Sports economic development needs based on perfect infrastructure, the transition in the social life style and sports consumption demand of internal force, through the sports commercial operation and management and thus become an important part of the national economic structure.This, on the one hand, rely on the government macro policy support and financial support, form the system of sports industry layout, on the other hand also cannot leave the self-regulation of the market economy, by adapting the public consumption demand, stimulate the diversification of sports consumption hot spots, promote the prosperity and development of the sports economy.
\end{abstract}

\section{Introduction}

Sports economy refers to the public demand for sports, sports entertainment, sports goods and other forms with the aid of the mode of production and business operation process and integration, to that of the associated economic bound to each other, creating new economic industry.With the development of national economy and residents' living standard gradually improve, the value of sports economy in the national economic structure will increasingly highlighted.Current sports in our country economic development still exist some shortcomings and backward compared with developed countries, the sports of our country to study the condition and the strategy of economic development, the development of the sports economic expansion to seek the path is important.

\section{Our country sports the inevitability of economic development}

Compared with the rigid demand for food and clothing live line, the development of sports economy is the inevitable result of social productivity after reaching a certain level. In social productivity is low, people life level is not high, under the condition of sports consumption demand will inevitably give in to the necessary material consumption, and the improvement of the economic basis is bound to be upgrading public consumption idea and consumption demand.

Sports economy was born, become the people entertainment, leisure, fitness.Social productivity by leaps and bounds in our country, the economic structure gradually optimized, under the new era of sports consumption has become an indispensable part of public life, develop the sports economy has become to promote the economic development of our country, the important measures for upgrading public cultural life consumption.

Public demand for sports has been exist in various stages of social development, as a matter of 
life necessities, sports goods, sports facilities, sports services such as project management as the core of sports economy as people come from the transformation of consumption concept and new consumer demand.From the aid of articles for daily use, the infrastructure of individual physical exercise to organize a collective sports activities, to constantly tend to be diversified, professional sports industry modernization, the public demand for sports have been made by the original physical fitness gradually developed to the leisure entertainment, decompression sent, used for sports products and facilities gradually realize the industrialization, professional production and management, thus we can detect the transformation and upgrading of the consumption idea.

In the great strategy of socialist modernization under the background, implement comprehensive fitness strategy, improve the national quality is to improve people's lives, improve the inevitable requirement of China's comprehensive national strength.To develop sports economy, service for the public to provide a variety of sports industry, widely publicized the importance of the mass sports value is the inner motive power of implementing comprehensive fitness strategy implementation.Sports development of the economy as well as comply with the demand of the public sports consumption upgrade necessity to guide people to a correct understanding of physical exercise, create new sports point of consumption is of great significance.Current sports economy has become an important part of national economy in our country, rich and colorful sports can satisfy people's consumption demand at all levels, from the level of public swimming, mountain climbing, badminton movement to higher consumption of golf, motor racing, shooting sports, provides consumers with diversified principle of space, this plays an important role in to speed up the pace of overall fitness.

\section{The basic conditions of sports economic development}

Sports economic development can meet the demand of professional sports competition, sports scientific research innovation needs, and mass physical fitness needs, these diverse sports and scientific research is inseparable from the support infrastructure.Sports development, therefore, one thing in common is all need certain places and sports equipment, which is one of the basic conditions of development of sports economy.For sports infrastructure construction funds mainly come from state funding, a public welfare not for-profit, popular sports to widely spread.Countries in construction of infrastructure is not by the regulation of market economy, but has significant administrative regulation characteristics. The emerging and development of sports economy in our country, has been constantly improving and optimizing sports infrastructure, especially in recent years, under the impetus of the construction of national slogan, local governments at all levels to speed up the pace of the sports infrastructure construction in rural areas, to stimulate economic growth has played an important role in rural sports.

As living standards improve public and popularization of developing trend of sports consumption, on the economic profit for the purpose of sports goods production gradually realize the industrialization and scale operation.

In an open market economy, sports commercialization aimed at public demands for the reality of sports consumption, in the transformation and upgrading of consumption patterns of provides more varieties of sports service for the public.Especially under the background of China's current economic rapid development era, which is mainly composed of a buyer's market economy has been forming, sports commercialization more market-driven.Predominantly social for-profit investment sports commercialization and predominantly national public welfare infrastructure construction with the attitude of complementary comprehensive drive the development of sports economy in our country.Sports commercialization in providing high quality services and goods also speeded up the 
social human and material resources, financial resources and other production resources and transformation of movement, the fuel economic growth, promote sports economy plays a positive role in line with international standards.

China's market economy system decides the sports economic development will inevitably to the market demand as the guidance, and mass consumption idea and consumption ability becomes around the market demand of the fundamental factors.On the one hand, the mass sports consumption idea transformation mainly based on the development of social productive forces, in after basic material consumption and to meet the food and clothing problem, according to the different levels can present travel alienation of mass sports consumption level, so the mass of sports consumption ability to pay is the fundamental factors influencing the market demand.On the other hand, the public's cultural degree, fitness consciousness was the key to affect the market demand. Sports as a strong body, cultivate one's morality raises a gender, sending pressure project, can you get the general public recognition and make them willing to pay for sports is of Paramount importance. Countries, therefore, the propaganda, the importance of sports popularization education also become the important factor affecting the mass consumption idea.

Although sports demand has been accompanied by the development of social productive forces, but on physical fitness, leisure and entertainment for the main purpose of sports is usually only occurs in people's leisure time, therefore, social life style type, the public to sport the length of time after the work has become an important conditions affect the economic development of sports.In social production constantly tend to automation, informationization, mechanization of modern social situation, to save a large amount of human capital, in the people's wealth accumulated at the same time more and more free time to come out, this provides necessary conditions for sports economic development.Since the reform and opening, our country people's social life style, great changes have taken place in pure labor to the creation of social wealth to the age of the past, the people are the pursuit to improve the production efficiency, so as to provide a time of rich and colorful way of life. Under this background, the sports economic development will enter the heyday.

\section{The sports economic development countermeasure and the suggestion}

Although sports economy with market regulation as the core, but the state of the sports industry macro policy guide are essential.The current rapid development of sports consumption demand market situation, the sports industry of our country's existing policy cannot fully adapt to the speed and scale of sports economic development, thus strengthen the policy support of government sports industry is extremely important.First of all, establish perfect sports financial support policies. The national finance funds from relatively single sports gradually extended to the infrastructure construction projects of scientific research, sports business, provide abundant funds support for the development of sports economy.Secondly, establish government regulation of the balanced development of the sports policies. Simply rely on market regulation, the sports economic development will inevitably appear uneven allocation of resources, sports consumption imbalance between supply and demand, etc.Countries to the relatively weak sports industry projects and regional adequate capital support and policy support, especially to stimulate the economy the rise and development of rural sports.

Sports industrialization is to from the planned economy overly dependent on the development pattern of change to come over, to establish the market demand oriented model of sports economic development.Industrialization of sports economy in operation and management should first cultivate function complete, reasonable structure, complete variety of sports market system.From 
the point of current status of economic development of our country sports, sports economy has covered sports entertainment, sports, sports tourism, sports performance, sports goods production and marketing, and other market areas. The improvement of the sports market and rich on the one hand, with the national macroeconomic regulation and control policy to the various market system, formed the standard market operation order and market regulation mechanism.On the other hand to push the interaction between various types of sports market, create new sports market in the industry interaction, guide the new sports consumption demand.

Origin lies in the physical fitness of sports development, improve people's physical quality, and with the people of entertainment and leisure, tourism, relaxation, such as the pursuit of spiritual life level enhancement, in addition to the abs as the main function of sports, many sports is given priority to with watching entertainment, performing sports also arises at the historic moment, at the same time, the sports investment, production and marketing of sports goods, sports lottery and other diversified market types have sprung up one after another.

Do a good job in the sports industry layout, regularize sports economic development in the socialist construction of relationship is extremely important.Aspect to the sports industry as an important part of national economy structure, sports investment is increased by creating new market hot spots and economic growth, and on this basis to promote the sports industry with the intersection of the second and the third industry. On the other hand will be on the basis of the existing sports market consistently seek project integration and industrial linkage, stimulating new consumer demand.

Under the impetus of the national fitness slogan, successive development of the sports infrastructure at all levels in our country, but for a long time because of the lack of scientific and effective management pattern, this part of the public sports facilities is underutilized resources, the result must be financial fund and the waste of social resources.

This, on the one hand, to pay attention to the importance of public sports infrastructure management, in the public utility services department set up specialized management positions and personnel, responsible for the maintenance of public sports facilities, maintenance and upgrading, so as to meet the demand of social public sports, to save the public sports venues construction funds has significant effect.On the other hand is to adjust the current government management of public sports installations and facilities management. To the government for the regulation many facets of the dominated by social management mode, in the construction of sports facilities after the completion of the introduction of social capital strength for facilities maintenance and upgrade. In the protection of public sports installations and facilities to make full use of resources at the same time stimulate the market enthusiasm to the greatest extent.

\section{Conclusion}

Sports economy is the rapid development of social productivity, the inevitable trend of social public consumption demand transformation, is also promoting economic transformation under the new era, important driving force to stimulate the sports consumption market.Sports is the national economic development policy, funding, macro-control and market economy of the dual role as a result, the self-adjustment so to play an important value of sports economy in the national economy structure is combined with two aspects of government, market, to meet consumer demand at the same time also want to upgrade to guide consumption. 


\section{Reference}

[1] Ming Jun. Sports economy development of the basic conditions and countermeasures [J]. Heilongjiang Science, 2016 (18).

[2] Ma Xiaoyun. Sports economy development of the basic conditions and countermeasures analysis [J]. Brand (second half), 2015 (10)

[3] Zhao Xiangwei. Sports economy development of the basic conditions and countermeasures [J]. Contemporary Sports Science and Technology, 2016 (04).

[4] Liu Chengyun. Sports economy in the national economic development status [J]. Sports Culture Guide, 2013 (04)

[5] Jia Guiyun. Sports economy on China's economic development of the extreme response [J]. Academic exploration, 2012 (03) 